ISSN = 1980-993X - doi:10.4136/1980-993X
www.ambi-agua.net
E-mail: ambi-agua@agro.unitau.br
Tel.: (12) 3625-4212

\title{
Avaliação da citogenotoxicidade de efluentes têxteis utilizando Allium cepa $\mathrm{L}$.
}

\author{
(http://dx.doi.org/10.4136/ambi-agua.198)
}

\author{
Luige Biciati Alvim ${ }^{1}$; Fábio Kummrow ${ }^{2}$; Luiz Alberto Beijo ${ }^{3}$; Cláudio Antônio de \\ Andrade Lima ${ }^{4}$; Sandro Barbosa ${ }^{5}$ \\ ${ }^{1}$ Departamento de Biologia Geral, UFMG - Universidade Federal de Minas Gerais, \\ e-mail: luigebiciati@yahoo.com.br \\ ${ }^{2}$ Departamento de Ciências Exatas e da Terra, Universidade Federal de São Paulo, \\ e-mail: fkummrow@unifesp.br \\ ${ }^{3}$ Instituto de Ciências Exatas, Unifal-MG - Universidade Federal de Alfenas, \\ e-mail: luizbeijo@yahoo.com.br \\ ${ }^{4}$ Instituto de Ciência e Tecnologia, Unifal-MG -Universidade Federal de Alfenas, \\ e-mail: engclaudiolima@gmail.com \\ ${ }^{5}$ Instituto de Ciências da Natureza, Unifal-MG - Universidade Federal de Alfenas, \\ e-mail: sandro.barbosa@unifal-mg.edu.br
}

\section{RESUMO}

O potencial citotóxico e genotóxico dos efluentes bruto (EB) e tratado (ET) de duas indústrias têxteis localizadas no sul de Minas Gerais, que tratam seus efluentes conjuntamente na mesma estação, foi investigado utilizando-se o sistema-teste Allium cepa. A citotoxicidade foi determinada a partir dos parâmetros alongamento de raízes e índice mitótico (IM) e a avaliação da genotoxicidade constou da determinação de anormalidades cromossômicas (AC). As amostras dos efluentes foram testadas nas concentrações 0, 25, 50, 75 e 100\% (v/v). Foi adotado um delineamento experimental inteiramente casualizado, com quatro repetições de 30 sementes. Constatou-se que as amostras, em quase todas as concentrações testadas, promoveram um aumento do comprimento radicular quando comparadas ao controle negativo, efeito possivelmente relacionado aos níveis de nutrientes e matéria orgânica presentes nos efluentes. Observou-se um menor IM em todas as concentrações do ET quando comparado ao EB, e os maiores IM foram observados na concentração $100 \%$ (v/v) de ambos efluentes. As maiores taxas de AC ocorreram nas concentrações $75 \%$ (v/v) do EB e 100\% (v/v) de ambos efluentes. Os efluentes não apresentaram ação citotóxica, entretanto a divisão celular ocorreu de forma desordenada, levando ao aumento da taxa de AC, o que caracteriza um efeito genotóxico. Melhorias no processo de tratamento desses efluentes são necessárias para que seus impactos ambientais sejam reduzidos.

Palavras-chave: Citogenotoxicidade; efluente têxtil; Allium cepa.

\section{Evaluation of the cytogenotoxicity of textile effluents using Allium cepa $\mathrm{L}$.}

\section{ABSTRACT}

The cytotoxic and genotoxic potential of the raw (EB) and treated (ET) effluents of two textile mills located in south of Minas Gerais State that have their effluents treated at the same Effluent Treatment Plant was investigated using the Allium cepa test system. Cytotoxicity was evaluated by the root elongation and mitotic index (MI) endpoints and the genotoxicity was assessed by de determination of chromosome aberrations (CA).The effluent samples were tested at the concentrations 0, 25, 50, 75, and $100 \%$ (v/v). A Completely Randomized Design with four replicates of 30 seeds was used. The effluent samples in almost all tested concentrations promoted an increase in root elongation compared to the negative control and this effect was probably related to nutrients levels and organic matter in effluent samples. A 
ALVIM, L. B.; KUMMROW, F.; BeiJO, L. A; LIMA, C. A. de A.; BARBOSA, S. Avaliação da citogenotoxicidade de efluentes têxteis utilizando Allium cepa L.. Ambi-Agua, Taubaté, v. 6, n. 2, p. 255-265, 2011. (doi:10.4136/ambi-agua.198)

lower MI at all concentrations of ET compared to EB. The highest MI was observed at $100 \%$ $(\mathrm{v} / \mathrm{v})$ concentration of both effluents. The highest rates of CA occurred at concentrations $75 \%$ $(\mathrm{v} / \mathrm{v})$ of EB and $100 \%(\mathrm{v} / \mathrm{v})$ of both effluents. The effluent samples showed no cytotoxic effect, but cell division occurred disorderly, leading to increase rate of AC, revealing a genetoxic effect. Improvements in the wastewater treatment are needed to reduce environmental impacts.

Keywords: Cytogenotoxicity; textile effluent; Allium cepa.

\section{INTRODUÇÃO}

O setor têxtil pode ser classificado como de médio a alto potencial poluidor (indústrias que possuem etapas de tingimento ou tinturaria), pois apresenta elevado consumo de água e energia elétrica, utiliza produtos tóxicos em seus processos e, além disso, produz e lança no meio ambiente grandes volumes de efluentes (Dellamatrice e Monteiro, 2006a,b; ArslanAlaton e Alaton, 2007; Mathur et al., 2007; Sharma et al., 2007; Abreu et al., 2008; Salgado et al., 2009).

O sul de Minas Gerais, de acordo com Diniz (2000), é uma das regiões detentoras da maior concentração de estabelecimentos têxteis do Estado. Os efluentes dessas indústrias, se não tratados adequadamente antes de serem lançados em águas naturais, são capazes de contaminar os mananciais e bacias de grande importância regional, levando as indústrias a se preocuparem em adequar seus sistemas de tratamento à legislação vigente, sendo essa também uma preocupação ecológica emergente (Immich, 2006).

Os efluentes gerados por esse setor apresentam, além da coloração intensa, grandes quantidades de sólidos suspensos, altos valores de demanda química de oxigênio (DQO), altos valores de demanda bioquímica de oxigênio (DBO), elevadas temperaturas, acidez ou alcalinidade (Liu et al., 2007). Entre as substâncias presentes estão metais, amido, surfactantes, dispersantes, óleos, emulsificantes, soda cáustica, solventes, sais orgânicos e inorgânicos e uma grande variedade de corantes (Alinsafi et al., 2006; Dellamatrice e Monteiro, 2006b; Liu et al., 2007; Mathur et al., 2007).

Quando a composição química dos efluentes é conhecida, os efeitos associados ao seu lançamento no corpo receptor podem ser avaliados utilizando-se métodos de estimativa de toxicidade baseados na estrutura molecular dos compostos presentes e na sua abundância. Porém, determinar quimicamente todos os toxicantes presentes nesse tipo de resíduo é uma tarefa impraticável. Além disso, a complexidade das relações entre os compostos e a biota, e o desconhecimento de alguns constituintes dos efluentes, associados a possíveis efeitos aditivos, sinérgicos ou antagônicos resultantes das interações entre os seus constituintes, demonstram que os dados obtidos por métodos embasados somente em análises químicas são, em muitos casos, inadequados para uma correta avaliação do potencial tóxico desse tipo de resíduo, sendo recomendável uma caracterização complementar com testes biológicos (Kapanen e Itavaara, 2001; Rosa et al., 2001; Wilke et al., 2008).

A Organização de Cooperação e de Desenvolvimento Econômico (OECD, 1984) descreve os testes de fitotoxicidade como uma das técnicas mais comuns na avaliação de compostos químicos. Vários autores (Grant, 1982; Chauhan et al., 1999; Guerra e Souza, 2002) descrevem a espécie Allium cepa L. como um eficiente sistema-teste usado rotineiramente para avaliar o potencial citogenotóxico de produtos químicos no ambiente devido a sua sensibilidade e boa correlação com outros bioensaios. Hauschild (1993) relata que qualquer mudança nas condições ambientais, principalmente por causa da poluição química, pode ser observada nas plantas pela redução do crescimento radicular. Assim, esse organismo é considerado muito eficiente para o biomonitoramento, especialmente de ambientes aquáticos poluídos (Fernandes et al. 2007; Caritá e Marin-Morales, 2008). 
ALVIM, L. B.; KUMMROW, F.; BeiJO, L. A; LIMA, C. A. de A.; BARBOSA, S. Avaliação da citogenotoxicidade de efluentes têxteis utilizando Allium cepa L.. Ambi-Agua, Taubaté, v. 6, n. 2, p. 255-265, 2011. (doi:10.4136/ambi-agua.198)

Nesse contexto, o objetivo deste trabalho foi avaliar a aplicabilidade do sistema Allium cepa, utilizando-se a variedade beta cristal, para investigar a citotoxicidade e genotoxicidade dos efluentes bruto e tratado de duas indústrias têxteis localizadas no sul do Estado de Minas Gerais, que tratam seus efluentes conjuntamente na mesma estação de tratamento de efluentes (ETE), a fim de subsidiar estratégias menos impactantes para disposição destes no ambiente.

\section{MATERIAL E MÉTODOS}

Amostra do efluente bruto e tratado foi coletada na ETE utilizando-se recipientes metálicos e seu transporte foi realizado em frascos de polietileno, sendo imediatamente encaminhadas para análise. A ETE em estudo emprega o tratamento biológico aeróbio por lodos ativados, modalidade aeração convencional, tratando despejos de tinturaria de fios de poliéster após tratamento físico-químico em flotador, com vazão média de cerca de $25 \mathrm{~m} 3 / \mathrm{h}$, sendo a sedimentação no decantador secundário também assistida quimicamente com adição de floculantes e polieletrólitos. Para o preparo das diluições das amostras de efluente foi utilizada água ultrapura, obtendo-se as seguintes concentrações: controle negativo (somente água ultrapura), 25, 50, 75 e 100\% (efluente não diluído) (v/v).

\subsection{Planejamento experimental}

Adotou-se um delineamento experimental inteiramente casualizado com quatro repetições de 30 sementes, sendo cada parcela experimental uma placa de Petri. Como organismo teste foi empregada a espécie Allium cepa L. var. beta cristal, gentilmente cedidas pela Embrapa Hortaliça (Brasília-DF).

\subsection{Avaliação da citotoxicidade}

Para a avaliação de efeitos citotóxicos, os parâmetros analisados foram o comprimento médio das raízes das sementes (CMR) e o índice mitótico (IM). Para isso, 30 sementes foram distribuídas em uma placa de Petri de vidro $(100 \times 15 \mathrm{~mm})$ tendo como substrato uma folha de papel-filtro umedecida com $3 \mathrm{~mL}$ das diferentes concentrações de efluente bruto e tratado (25, 50, 75 e 100\% v/v), permanecendo por 5 dias em câmara de germinação com luz constante e temperatura de $20^{\circ} \mathrm{C}$. Água ultrapura foi empregada como controle negativo.

O CMR foi determinado pela média do tamanho de 16 raízes para cada uma das concentrações dos efluentes. Essas raízes corresponderam às 4 maiores existentes em cada uma das repetições (placas de Petri). Para essa aferição, utilizou-se um paquímetro simples do tipo universal. Após a aferição do comprimento, as pontas das raízes foram coletadas, prétratadas e fixadas de acordo com Barbosa et al. (2003). Para determinar o IM foi utilizada a seguinte equação: $\mathbf{I M}=\mathbf{N C M} / \mathbf{N T C} \times \mathbf{1 0 0}$, em que NCM corresponde ao número de células em mitose e NTC ao número total de células analisadas. Foram analisadas 1000 células por tratamento, sendo para cada tratamento dez lâminas e 100 células por lâmina.

\subsection{Avaliação da genotoxicidade}

A análise da atividade genotóxica constou da investigação de anormalidades cromossômicas (AC) nas células de raízes das sementes de A. cepa. Assim como na avaliação de citotoxicidade, foram analisadas 1000 células por tratamento, sendo para cada tratamento dez lâminas e 100 células por lâmina.

As lâminas foram confeccionadas utilizando-se as pontas das raízes das sementes germinadas nos diferentes tratamentos, sendo referentes aos efluentes bruto e tratado nas concentrações 25, 50, 75 e 100\% (v/v), água ultrapura como controle negativo e sulfato de alumínio, na concentração $1 \times 10^{-3} \mathrm{M}$, como controle positivo. 
ALVIM, L. B.; KUMMROW, F.; BeiJO, L. A; LIMA, C. A. de A.; BARBOSA, S. Avaliação da citogenotoxicidade de efluentes têxteis utilizando Allium cepa L.. Ambi-Agua, Taubaté, v. 6, n. 2, p. 255-265, 2011. (doi:10.4136/ambi-agua.198)

Após o período de germinação, as raízes foram coletadas, fixadas em solução de Carnoy (álcool e ácido acético na proporção 3:1 v/v) por 24 horas, lavadas duas vezes com água destilada, hidrolisadas em $\mathrm{HCl} 5 \mathrm{M}$ por 20 minutos em temperatura ambiente, lavadas novamente e coradas com Reativo de Schiff por 45 minutos (na ausência de luz). Após esses procedimentos, o meristema foi coletado, adicionado uma gota de ácido acético $45 \%$ e a lâmina confeccionada pelo método de esmagamento. As análises citogenéticas foram conduzidas de acordo com o procedimento descrito por Guerra e Souza (2002).

\subsection{Análise estatística}

Os dados de citotoxicidade foram submetidos à análise de variância e as médias comparadas por meio do teste Scott-Knott utilizando-se o programa estatístico Sisvar versão 4.0. Para análise dos dados da avaliação de genotoxicidade foi realizado um teste não paramétrico, sendo as médias comparadas pelo teste de Kruskal-Wallis, com auxílio do programa BioEstat 5.0. Todas as análises foram realizadas no nível de significância de 5\%.

\section{RESULTADOS E DISCUSSÃO}

A variedade beta cristal de A. cepa, foi selecionada para o experimento desenvolvido neste trabalho devido à sua rapidez e alta taxa de germinação, comprovada em estudos preliminares (dados não apresentados). Além disso, o comportamento cromossômico dessa espécie é conhecido, permitindo a obtenção de resultados consistentes.

Não foi observada citotoxicidade para as amostras de efluente bruto e tratado frente ao parâmetro alongamento de raízes (Figura 1). Para todas as concentrações testadas do efluente tratado e para as mais diluídas do efluente bruto ( 25 e $50 \% \mathrm{v} / \mathrm{v})$ observou-se um efeito promotor do crescimento das raízes. As concentrações menos diluídas do efluente bruto (75 e $100 \% \mathrm{v} / \mathrm{v}$ ) apresentaram alongamento de raízes similar ao controle negativo. Particularmente, no caso das concentrações de 75 e 100\% (v/v) do efluente bruto, a ausência desse efeito promotor de crescimento pode estar relacionado à menor diluição de componentes tóxicos, como, por exemplo, os corantes têxteis e metais pesados, possivelmente presentes nesse efluente.

Nilsen e Rank (1994) também não encontraram efeito inibitório para o alongamento de raízes expostas a efluentes de duas indústrias de corantes têxteis. Resultados opostos foram obtidos por Samuel et al. (2010) que verificaram um significativo efeito inibitório de um efluente têxtil para raízes de bulbos de $A$. cepa, não havendo crescimento algum de raízes nas concentrações superiores a $30 \%(\mathrm{v} / \mathrm{v})$. Com base nesses dados, os autores consideraram esse parâmetro importante para a avaliação ecotoxicológica de efluentes industriais (Samuel et al., 2010).

A toxicidade dos efluentes têxteis bruto e tratado para o parâmetro alongamento de raízes também foi avaliado por Rehman et al. (2009). As espécies utilizadas foram Raphanus sativus, Brassica campestris e Brassica rapa, sendo observada diminuição do alongamento das raízes das três espécies quando expostas às diferentes diluições do efluente bruto, sendo menos intensos nas menores concentrações de efluente. O efeito inibitório foi mais pronunciado para B. rapa. Porém, para o efluente tratado apenas uma pequena diminuição no alongamento de raízes foi observada e, nas menores concentrações, também foi verificado um efeito promotor de crescimento (Rehman et al., 2009). Jadhav et al. (2010) também observaram um importante decréscimo da fitotoxicidade do efluente têxtil tratado em relação ao bruto para as espécies Triticum aestivum e Phaseolus mungo nos parâmetros germinação de sementes e alongamento de raízes. Nesse estudo os autores concluíram que os efluentes têxteis brutos representam um perigo para o meio ambiente, principalmente quando aplicados a agricultura (Jadhav et al., 2010). 
ALVIM, L. B.; KUMMROW, F.; BeiJO, L. A; LIMA, C. A. de A.; BARBOSA, S. Avaliação da citogenotoxicidade de efluentes têxteis utilizando Allium cepa L.. Ambi-Agua, Taubaté, v. 6, n. 2, p. 255-265, 2011. (doi:10.4136/ambi-agua.198)

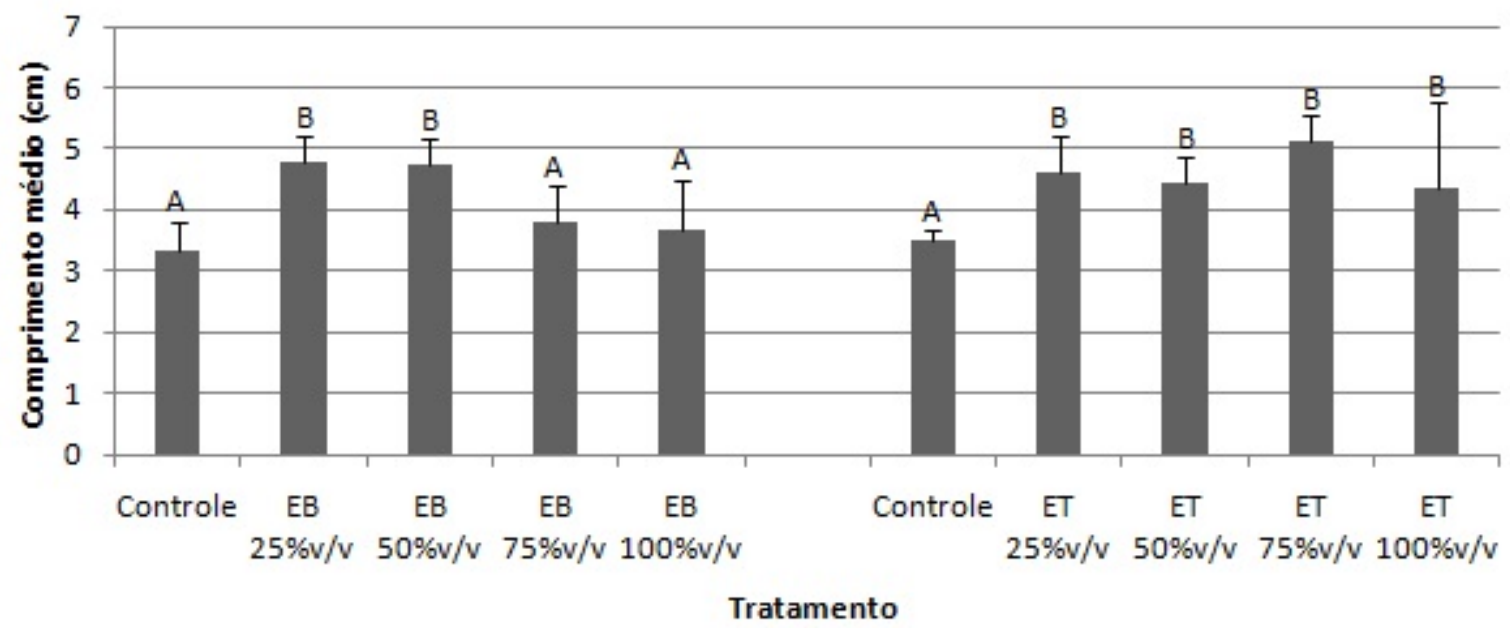

Figura 1. Comprimento médio das raízes de Allium cepa L. expostas às diferentes concentrações dos efluentes bruto (EB) e tratado (ET). Colunas seguidas por letras distintas diferem entre si $(\mathrm{p}<0,05)$ pelo teste Scott-Knott.

A ETE da qual as amostras foram coletadas emprega o sistema de tratamento biológico com lodo ativado. Apesar de suas inúmeras vantagens, esse tipo de tratamento remove entre 10 e 30\% da matéria orgânica presente nos efluentes (Cecen, 1999). O efluente bruto estudado apresentou valores DQO e DBO de $2302 \pm 949$ e $564 \pm 307$ mg/L, respectivamente. Para manutenção das condições ideias de nutrientes, durante a biodegradação aeróbia, a ETE operava com efluente bruto apresentando cerca de $30 \mathrm{mg} / \mathrm{L}$ de Nitrogênio Total e $5 \mathrm{mg} / \mathrm{L}$ de Fósforo Total, sendo adicionado quando necessário ureia e fosfato trisódico, com perda no efluente final tratado de cerca de $10 \%$ da quantidade inicial para os respectivos macronutrientes. No entanto, durante o período em estudo, a ETE apresentou elevada eficiência na remoção de matéria orgânica em termos de DQO e DBO, $90 \pm 6$ e $92 \pm 13$ mg/L, respectivamente, gerando um efluente tratado que atende aos padrões de lançamento da legislação ambiental vigente no Estado de Minas Gerais.

A matéria orgânica presente no efluente bruto, a matéria não removida durante o tratamento e os macronutrientes podem estimular o alongamento radicular, diminuindo a sensibilidade do teste e/ou mascarando um possível efeito tóxico (Rodrigues e Bianchini, 2007). Nesse contexto, os nutrientes presentes nesses resíduos (por exemplo, Nitrogênio e Fósforo), bem como elevada carga de matéria orgânica presente no efluente bruto e a carga remanescente observada no efluente tratado possuem efeito promotor ao alongamento de raízes. Como ocorre com os nutrientes, parte da carga orgânica do efluente final pode vir do próprio efluente bruto, proveniente do processo industrial, e parte pode ser adicionada durante o tratamento biológico (Eremektar et al., 2007).

Além do alongamento das raízes, o índice mitótico (IM) também foi utilizado como parâmetro para avaliar a citotoxicidade dos efluentes. Índices mitóticos significativamente menores que aqueles do controle negativo podem indicar alterações provenientes da ação de substâncias químicas no crescimento e desenvolvimento dos organismos expostos e IM maiores que o controle negativo resultam do aumento na divisão celular, podendo ser prejudicial às células, levando a proliferação celular desordenada e, eventualmente, a formação de tumores (Leme e Marin-Morales, 2009). Ambos efluentes avaliados apresentaram, em todas as concentrações testadas, um maior IM em relação ao controle negativo, sendo os maiores valores encontrados nas concentrações $100 \%$ (v/v) de ambos os tipos de efluentes (Figura 2). 
AlviM, L. B.; KUMMROW, F.; BEIJO, L. A; LIMA, C. A. de A.; BARBOSA, S. Avaliação da citogenotoxicidade de efluentes têxteis utilizando Allium cepa L.. Ambi-Agua, Taubaté, v. 6, n. 2, p. 255-265, 2011. (doi:10.4136/ambi-agua.198)

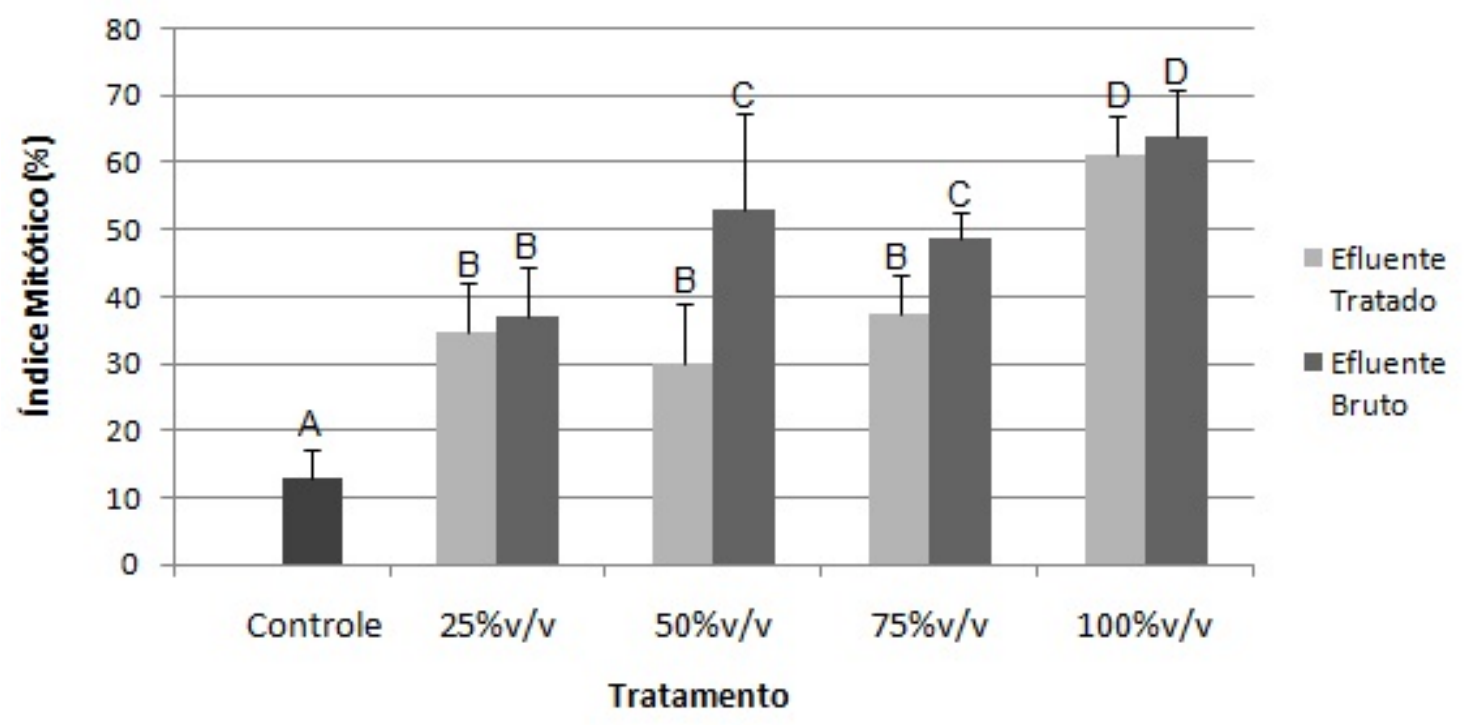

Figura 2. Índice mitótico em células de raiz de Allium cepa L. expostas às diferentes concentrações dos efluentes têxteis. Foram analisadas 1000 células por tratamento. Colunas seguidas por letras distintas diferem entre si $(\mathrm{p}<0,05)$ pelo teste Scott-Knott.

Diferentes autores observaram que efluentes provenientes da produção de corantes e de processos têxteis exercem efeitos sobre os cromossomos e a divisão celular (Jadhav et al., 2010). No estudo conduzido por Jadhav et al. (2010), efluentes têxteis tratados por um consórcio de bactérias, apresentaram IM na mesma faixa do controle negativo. Samuel et al. (2010) observaram evidente diminuição do IM com o aumento das concentrações de efluente têxtil.

Segundo Leme e Marin-Morales (2009), as anormalidades cromossômicas (AC) em células de Allium cepa L. são um parâmetro eficiente para a investigação do potencial genotóxico de um efluente têxtil, pois fornecem informações importantes que devem ser consideradas no biomonitoramento ambiental. O IM também é utilizado nessa avaliação como parâmetro para assegurar que a fitotoxicidade se encontra abaixo dos níveis aceitáveis para a observação das taxas de AC (Nilsen e Rank, 1994). Assim, para investigar a presença de compostos genotóxicos nas amostras de efluente foi realizada a avaliação da genotoxicidade em células meristemáticas. Dentre as possíveis AC, as mais frequentes para as amostras analisadas, foram os micronúcleos (MN), as pontes anafásicas (PA) e distúrbios metafásicos (DTM), como a C-metáfase. Os resultados obtidos são apresentados na Tabela 1.

As maiores taxas de AC ocorreram nas concentrações 75 e 100\% (v/v) do efluente bruto, com valores aproximadamente 6 vezes maiores que o controle negativo. A concentração $100 \%$ (v/v) do efluente tratado também apresentou uma alta taxa de AC, em torno de 4 vezes maior que o controle negativo, revelando o efeito genotóxico de ambos efluentes. Além disso, a alta frequência de AC observada para a amostra de efluente tratado sugere uma baixa eficiência do tratamento no que diz respeito à remoção de compostos genotóxicos, fator que causa grande preocupação, uma vez que este está sendo lançado em corpos d’água da região. 
ALVIM, L. B.; KUMMROW, F.; BeiJO, L. A; LIMA, C. A. de A.; BARBOSA, S. Avaliação da citogenotoxicidade de efluentes têxteis utilizando Allium cepa L.. Ambi-Agua, Taubaté, v. 6, n. 2, p. 255-265, 2011. (doi:10.4136/ambi-agua.198)

Tabela 1. Anormalidades cromossômicas induzidas em células de raiz de Allium cepa pelo efluente tratado e bruto em diferentes concentrações em relação aos controles negativo e positivo.

\begin{tabular}{c|ccl|c}
\hline $\begin{array}{c}\text { Tratamento } \\
(\mathbf{v} / \mathbf{v})\end{array}$ & MN & PA & DTM & Total de Anormalidades \\
\hline ET 25\% & $0,8^{\mathrm{a}}$ & $0,8^{\mathrm{ns}}$ & $0^{\mathrm{ns}}$ & $1,8^{\mathrm{ns}}$ \\
ET 50\% & $0,2^{\mathrm{a}}$ & $0,8^{\mathrm{ns}}$ & $0,4^{\mathrm{ns}}$ & $2,0^{\mathrm{a}}$ \\
ET 75\% & $0,2^{\mathrm{a}}$ & $1,0^{\mathrm{a}}$ & $0,9^{\mathrm{a}}$ & $2,5^{\mathrm{a}}$ \\
ET 100\% & $0,6^{\mathrm{a}}$ & $1,1^{\mathrm{a}}$ & $1,3^{\mathrm{a}, \mathrm{b}}$ & $3,6^{\mathrm{b}}$ \\
EB 25\% & $0,7^{\mathrm{a}}$ & $1,2^{\mathrm{a}, \mathrm{b}}$ & $0,6^{\mathrm{ns}}$ & $2,8^{\mathrm{a}, \mathrm{b}}$ \\
EB 50\% & $0,6^{\mathrm{a}}$ & $0,4^{\mathrm{ns}}$ & $1,3^{\mathrm{a}, \mathrm{b}}$ & $3,2^{\mathrm{b}}$ \\
EB 75\% & $1,0^{\mathrm{a}}$ & $1,5^{\mathrm{a}, \mathrm{b}}$ & $1,4^{\mathrm{a}, \mathrm{b}}$ & $4,6^{\mathrm{b}}$ \\
EB 100\% & $1,4^{\mathrm{a}}$ & $1,9^{\mathrm{a}, \mathrm{b}}$ & $1,6^{\mathrm{a}, \mathrm{b}}$ & $5,4^{\mathrm{b}}$ \\
CN & $0,4^{\mathrm{a}}$ & $0,3^{\mathrm{ns}}$ & $0,05^{\mathrm{ns}}$ & $0,85^{\mathrm{a}}$ \\
CP & $10,3^{\mathrm{b}}$ & $0,05^{\mathrm{ns}}$ & $0^{\mathrm{ns}}$ & $10,4^{\mathrm{b}}$ \\
\hline
\end{tabular}

ET: Efluente tratado; EB: Efluente bruto; CN: Controle negativo; CP: Controle positivo; MN: Micronúcleos; PA: Pontes anafásicas; DTM: Distúrbios metafásicos; ${ }^{a}$ p $<0,05$ em relação ao controle positivo CP; ${ }^{b} \mathrm{p}<0,05$ em relação ao $\mathrm{CN}^{\text {ns }}$ Valor não significativo estatisticamente. Médias nas colunas comparadas pelo teste Kruskal-Wallis.

Quando comparado a outros trabalhos que analisaram a ação de efluentes têxteis em bioensaios com plantas superiores, o presente estudo apresenta os mesmos níveis (Rank e Nielsen, 1998; Migid et al., 2007) ou menores frequências de anormalidades cromossômicas (Matsumoto et al., 2006; Egito et al., 2007). Samuel et al. (2010) observaram um aumento de aberrações cromossômicas que não estava relacionado à dose, ou seja, não era dose dependente. Porém, para os parâmetros PA e fragmentação houve uma diminuição de frequência nas concentrações maiores de efluentes, as quais foram atribuídas à toxicidade, responsável em inibir a divisão celular (Samuel et al., 2010). Ainda, quando nossos dados são comparados ao trabalho de Caritá e Marin-Morales (2008), também realizado no Brasil, resultados semelhantes foram observados. Ao contrário dos resultados apresentados acima, Nilsen e Rank (1994) não observaram efeitos genotóxicos para efluentes de indústrias que utilizam em seus processos corantes têxteis. Jadhav et al. (2010) verificaram que após o tratamento biológico empregado em seu estudo houve uma importante redução da coloração do efluente, da DBO, da DQO e do nível de metais pesados e, como consequência, uma redução significativa na porcentagem total de células mitóticas aberrantes.

A presença de micronúcleo é um parâmetro simples e eficiente para analisar o efeito mutagênico promovido por compostos químicos (Leme e Marin-Morales, 2009). A taxa de micronúcleos observada entre as diferentes concentrações dos efluentes não diferiram significativamente do controle negativo, apenas do controle positivo utilizado, que segundo Machado (1997) é capaz de induzir elevado número de MN. Resultado contrário ao observado neste trabalho foi descrito por Caritá e Marin-Morales (2008) que detectaram diferença estatística significativa na concentração 100\% (v/v) de um efluente têxtil.

Os DTM foram observados nas concentrações mais altas do efluente bruto (50, 75 e $100 \% \mathrm{v} / \mathrm{v}$ ) e tratado (75 e $100 \% \mathrm{v} / \mathrm{v}$ ), todas as concentrações apresentaram taxas aproximadamente 25 vezes maiores que o controle negativo. A presença de DTM caracteriza um efeito genotóxico leve pelo fato de ser uma alteração reversível durante o ciclo celular. Entretanto, alguns desses DTM podem induzir a formação de células poliploides que não são reversíveis, por isso a importância em quantificá-los (Odeigah et al., 1997). A presença de PA foi verificada nas concentrações mais altas do efluente tratado (75 e $100 \% \mathrm{v} / \mathrm{v}$ ) e em todas as concentrações do efluente bruto, exceto a de $50 \%(\mathrm{v} / \mathrm{v})$, confirmando o potencial genotóxico das amostras. 
ALVIM, L. B.; KUMMROW, F.; BeiJO, L. A; LIMA, C. A. de A.; BARBOSA, S. Avaliação da citogenotoxicidade de efluentes têxteis utilizando Allium cepa L.. Ambi-Agua, Taubaté, v. 6, n. 2, p. 255-265, 2011. (doi:10.4136/ambi-agua.198)

\section{CONCLUSÕES}

Os efluentes analisados promoveram um aumento tanto do índice mitótico como na taxa de anormalidades cromossômicas, demonstrando assim que estes apresentam uma atividade citogenotóxica.

Frente ao parâmetro alongamento de raízes os efluentes tiveram um efeito promotor de crescimento e não foi constatada citotoxicidade. Esse resultado pode estar relacionado à presença dos macronutrientes adicionados e/ou não removidos completamente durante o processo de tratamento biológico empregado, bem como a carga de matéria orgânica em ambas as amostras.

O tratamento biológico empregado na ETE avaliada é eficaz para a redução da citogenotoxicidade dos efluentes têxteis, porém não elimina completamente os efeitos dos componentes tóxicos, demostrando assim a necessidade de melhorias no processo empregado. Outros bioensaios e novos parâmetros podem e devem ser utilizados para melhor entender a toxicidade desse tipo de resíduo industrial. Análises químicas são de extrema importância para a identificação de poluentes prioritários presentes nos efluentes finais. Até que a citogenotoxicidade dos efluentes tratados seja completamente eliminada, a disposição desses resíduos em corpos d’água receptores deve ser repensada.

\section{AGRADECIMENTOS}

À FAPEMIG pelo apoio financeiro e à Embrapa Hortaliça (Brasília-DF) pelas sementes de Allium cepa L. var. beta cristal.

\section{REFERÊNCIAS}

ABREU, M. C. S.; SILVA-FILHO, J. C. L.; OLIVEIRA, B. C.; HOLANDA-JÚNIOR, F. L. Perfis estratégicos de conduta social e ambiental: estudos na indústria têxtil nordestina. Gestão \& Produção, São Carlos, v. 15, n. 1, p. 159-172, 2008.

ALINSAFI, A.; MOTTA, M.; LE BONTÉ, S.; PONS, M. N.; BENHAMMOU, A. Effect of variability on the treatment of textile dyeing wastewater by activated sludge. Dyes Pigments, London, v. 69, p. 31-39, 2006. http://dx.doi.org/10.1016/j.dyepig.2005.02.014

ARSLAN-ALATON, I.; ALATON, I. Degradation of xenobiotics originating from the textile preparation, dyeing and finishing industrial using ozonation and advanced oxidation. Ecotoxicology and Environmental Safety, New York, v. 68, p. 98-107, 2007. http://dx.doi.org/10.1016/j.ecoenv.2006.03.009

BARBOSA, S.; DAVIDE, L. C.; PEREIRA, A. V. Cytogenetics of Pennisetum purpureum schumck $x$ Pennisetum glaucum L. hybrids and their parents. Ciência e Agrotecnologia, Lavras, v. 27, p. 26-35, 2003.

CARITÁ, R.; MARIN-MORALES, M. A. Induction of chromosome aberrations in the Allium cepa test system caused by the exposure of seeds to industrial effluents contaminated with azo dyes. Chemosphere, Oxford, v. 72, p. 722-725, 2008.

CECEN, F. Investigation of substrate degradation and nonbiodegradable portion in several pulp beaching wastes. Water Science and Technology, Oxford, v. 40, p. 305-312, 1999. http://dx.doi.org/10.1016/S0273-1223(99)00732-5 
AlviM, L. B.; KUMMROW, F.; BEIJO, L. A; LIMA, C. A. de A.; BARBOSA, S. Avaliação da citogenotoxicidade de efluentes têxteis utilizando Allium cepa L.. Ambi-Agua, Taubaté, v. 6, n. 2, p. 255-265, 2011. (doi:10.4136/ambi-agua.198)

CHAUHAN, L. K. S.; SAXENA, P. M.; GUPTA, S. K. Cytogenetics effects of cypermethrinand fenvalerate on the root meristem cells of Allium cepa. Environmental and Experimental Botany, Oxford, v. 42, p. 181-189, 1999.

http://dx.doi.org/10.1016/S0098-8472(99)00033-7

DELLAMATRICE, P. M.; MONTEIRO, R. T. R. Toxicidade de resíduos têxteis tratados por microorganismos. Journal of the Brazilian Society of Ecotoxicology, Rio Grande, v. 1, p. 63-66, 2006a.

DELLAMATRICE, P. M.; MONTEIRO R, T. R. Decolorization and toxicity of municipal waste by horseradish (Cochlearia armoracia). Química Nova, São Paulo, v. 29, n. 3, p. 419-421, 2006b.

DINIZ, C. C. Distribuição regional da indústria mineira. Nova Economia, Belo Horizonte, v. 10, p. 39-69, 2000.

EGITO, L. C. M.; MEDEIROS M. G.; MEDEIROS, S. R. B.; AGNEZ-LIMA, L. F. Cytotoxic and genotoxic potential of surface water from the Pitimbu river, northeastern/RN Brazil. Genetics and Molecular Biology, Ribeirão Preto, v. 30, n. 2, p. 435-441, 2007.

EREMEKTAR , G.; SELCUK, H.; MERIC S. Investigation of the relation between COD fractions and the toxicity in a textile finishing industry wastewater: Effect of preozonation. Desalination, Amsterdam, v. 211, p. 314-320, 2007.

http://dx.doi.org/10.1016/j.desal.2006.02.096

FERNANDES, T. C. C.; MAZZEO, D. E. C.; MARIN-MORALES, M. A. Mechanism of micronuclei formation in polyploidizated cells of Allium cepa exposed to trifluralin herbicide. Pesticide Biochemistry and Physiology, New York, v. 88, p. 252-259, 2007. http://dx.doi.org/10.1016/j.pestbp.2006.12.003

GRANT, W. F. Chromosome aberration assays in Allium. A report of the US environmental protection agency gene-tox program. Mutation Research, Amsterdam, v. 99, p. 273291, 1982.

GUERRA, M.; SOUZA, M. J. Como observar cromossomos: um guia de técnica em citogenética vegetal, animal e humana. São Paulo: FUNPEC, 2002. 131p.

HAUSCHILD, M. Z. Chromium content of leaves reveals chromium (III): stress of higher plants before sensitive biomarkers. The Science of the total environment, Amsterdam, v. 1, p. 1345-1352, 1993.

IMMICH, A. P. S. Remoção de corantes de efluentes têxteis utilizando folhas de Azadirachta indica como adsorvente. 2006. Dissertação (Mestrado em Engenharia Química) - Universidade Federal de Santa Catarina, Florianópolis, 2006.

JADHAV, J. P.; KALYANI, D. C.; TELKE, A. A.; PHUGARE, S. S.; GOVINDWAR, S. P. Evaluation of the efficacy of a bacterial consortium for the removal of color, reduction of heavy metals, and toxicity from textile dye effluent. Bioresource Technology, Barking, v.101, p. 165-173, 2010.

KAPANEN, A.; ITAVAARA, M. Ecotoxicity tests for compost applications. Ecotoxicology and Environmental Safety, New York, v. 49, p. 1-16, 2001. http://dx.doi.org/10.1006/eesa.2000.1927 
ALVIM, L. B.; KUMMROW, F.; BeiJO, L. A; LIMA, C. A. de A.; BARBOSA, S. Avaliação da citogenotoxicidade de efluentes têxteis utilizando Allium cepa L.. Ambi-Agua, Taubaté, v. 6, n. 2, p. 255-265, 2011. (doi:10.4136/ambi-agua.198)

LEME, D. M.; MARIN-MORALES, M. A. Allium cepa Test in environmental monitoring: a review on its application. Mutation Research, Amsterdam, v. 682, p. 71-81, 2009. http://dx.doi.org/10.1016/j.mrrev.2009.06.002

LIU, R.; CHIU, H. M.; SHIAU, C.; YEH, R.Y.; HUNG, Y. Degradation and sludge production of textile dyes by Fenton and photo-Fenton processes. Dyes Pigments, London, v. 73, p. 1-6, 2007. http://dx.doi.org/10.1016/j.dyepig.2005.10.002

MACHADO, P. L. O. A. Considerações gerais sobre a toxicidade do alumínio nas plantas. Rio de Janeiro: EMBRAPA-CNPS, 1997. 22p.

MATHUR, N.; BHATNAGAR, P.; MOHAN, K.; BAKRE, P.; NAGAR, P.; BIJARNIA, M. Mutagenic evaluation of industrial sludge from common effluent treatment plant. Chemosphere, Oxford, v. 67, p. 1229-1235, 2007.

http://dx.doi.org/10.1016/j.chemosphere.2006.10.073

MATSUMOTO, S. T.; MANTOVANI, M. S.; MALAGUTTII, M. I. A.; DIAS, A. L.; FONSECA, I. C.; MARIN-MORALES, M. A. Genotoxicity and mutagenicity of water contaminated with tannery effluents, as evaluated by the micronucleus test and comet assay using the fish Oreochromis niloticus and chromosome aberrations in onion roottips. Genetics and Molecular Biology, Ribeirão Preto, v. 29, p. 148-158, 2006.

MIGID, H. M. A.; AZAB, Y. A.; IBRAHIM, W. M. Use of plant genotoxicity bioassay for the evaluation of efficiency of algal biofilters in bioremediation of toxic industrial effluent. Ecotoxicology and Environmental Safety, New York, p. 66, p. 57-64, 2007.

NILSEN, M. H.; RANK, J. Screening of toxicity and genotoxicity in wastewater by the use of the Allium test. Hereditas, Oxford, v. 121, p. 249-254, 1994.

http://dx.doi.org/10.1111/j.1601-5223.1994.00249.x

ODEIGAH, P. G. C.; NURUDEEN, O.; AMUND, O. O. Genotoxicity of oil field wastewater in Nigeria. Hereditas, Oxford, v. 126, 161-167, 1997. http://dx.doi.org/10.1111/j.16015223.1997.00161.x

ORGANIZATION FOR ECONOMIC CO-OPERATION AND DEVELOPMENT - OECD. OECD guidelines for testing of chemicals: terrestrial plants growth test. Paris, 1984. $11 p$.

RANK, J.; NIELSEN, M. H. Genotoxicity testing of wastewater sludge using the Allium cepa anaphase-telophase chromosome aberration assay. Mutation Research, Amsterdam, v. 418, p. 113-119, 1998.

REHMAN, A.; BHATTI, H. N.; ATHAR, H. Textile effluents affected seed germination and early growth of some winter vegetable crops: a case study. Water Air Soil Pollution, Dordrecht, v. 198, p. 155-163, 2009. http://dx.doi.org/10.1007/s11270-008-9834-5

RODRIGUES, S. C.; BIANCHINI, A. Extraction and concentration of freshwater - andseawater - derived dissolved organic matter for use in aquatic toxicology studies. Journal of the Brazilian Society of Ecotoxicology, Rio Grande, v. 2, n. 3, p. 275-281, 2007.

ROSA, E. V. C.; SIMIONATTO, E. L.; SIERRA, M. M. S.; BERTOLI, S. L.; RADETSKI, C. M. Toxicity-based criteria for the evaluation of textile wastewater treatment efficiency. Environmental Toxicology and Chemistry, Pensacola, v. 20, p. 839-845, 2001. 
AlViM, L. B.; KUMMrOW, F.; BeIJO, L. A; LiMA, C. A. de A.; BARBOSA, S. Avaliação da citogenotoxicidade de efluentes têxteis utilizando Allium cepa L.. Ambi-Agua, Taubaté, v. 6, n. 2, p. 255-265, 2011. (doi:10.4136/ambi-agua.198)

SALGADO, B. C. B.; NOGUEIRA, M. I. C.; RODRIGUES, K. A.; SAMPAIO, G. M. M.; BUARQUE, H. L. B.; ARAÚJO, R. S. Descoloração de efluentes aquosos sintéticos e têxtil contendo corantes índigo e azo via processos Fenton e foto-assistidos (UV e UV/H2O2). Engenharia Sanitária e Ambiental, Rio de Janeiro, v. 14, p. 1-8, 2009.

SAMUEL, O. S.; OSUALA, F. I.; ODEIGAH, P. G. C. Cytogenotoxicity evaluation of two industrial effluents using Allium сера assay. African Journal of Environmental Science and Technology, Victoria Island, v. 4, n. 1, p. 21-27, 2010.

SHARMA, K. P.; SHARMA, S.; SHARMA, S.; SINGH, P. K.; KUMAR, S.; GROVE, R. et al. A comparative study on characterization of textile waste waters (untreated and treated) toxicity by chemical and biological tests. Chemosphere, Oxford, v. 69, p. 4854, 2007. http://dx.doi.org/10.1016/j.chemosphere.2007.04.086

WILKE, B. M.; RIEPERT, F.; KOCH, C.; KÜHNE, T. Ecotoxicological characterization of hazardous wastes. Ecotoxicology and Environmental Safety, New York, v. 70, p. 283-293, 2008. http://dx.doi.org/10.1016/j.ecoenv.2007.10.003 